\title{
Mechanisms of Trastuzumab Resistance and Opportunities to Overcome Therapeutic Resistance
}

Milos Dokmanovic and Wen Jin Wu*

Laboratory of Molecular Oncology, Division of Monoclonal Antibodies, Office of Biotechnology Products, Office of Pharmaceutical Science, Center for Drug Evaluation and Research, U.S. Food and Drug Administration, Bethesda, Maryland, USA

Trastuzumab is a humanized monoclonal antibody directed against extracellular domain IV of Human Epidermal Growth Factor Receptor 2 (HER2) and is approved for the treatment of HER2-positive breast cancers either alone or in combination with chemotherapeutic agents $[1,2]$. HER2 is a member of HER/ErbB family of receptor tyrosine kinases, which play important role in breast cancer development and progression [1]. HER2 is overexpressed in approximately $20-30 \%$ of invasive breast cancer and is associated with poor disease-free survival and poor response to chemotherapy [3-5]. Over the past two decades, the development of monoclonal antibodies targeting HER2 has been intensely pursued as important cancer therapeutic strategy. While treatment with trastuzumab very successfully improves outcomes for women with HER2-positive breast cancer, therapeutic resistance to trastuzumab, including primary and acquired resistance, pose a significant hurdle in the treatment of HER2-positive breast cancers $[2,6,7]$, Better understanding of molecular mechanisms underlying primary or acquired resistance to trastuzumab is critical to improving the survival of patients with HER2-positive breast cancer.

Based on cell culture, xenograft models and clinical studies, mechanisms of trastuzumab resistance can be generally grouped as either related to the aberrant HER2 receptor signaling at the cell surface or to the deregulated signaling of the intracellular molecular players downstream of HER2 receptor [2]. The examples of the aberrant HER2 signaling at the cell surface include expression of p95HER2 truncated form which lacks the extracellular trastuzumab-binding domain [8], overexpression of MUC4 glycoprotein on the cell surface, which blocks trastuzumab binding site on HER2 [9], increased heterodimerization of HER2 with other HER family members such as HER1/EGFR [10] or with other receptor tyrosine kinases such as IGF-IR [11]. Among downstream molecular players whose deregulation may contribute to trastuzumab resistance are upregulation of small GTPase, Rac1 and IQGAP1 [12,13] leading to the inhibition of trastuzumabinduced degradation of HER2 [13], loss of PTEN [14] and expression of activating mutations in the PI3K (PIK3CA) [15], both of which result in hyperactivation of the PI3K/Akt signaling pathway, and upregulation of Src activity [16], which can further activate HER1 and HER3 and promote trastuzumab resistance in a PI3K/Akt-dependent or PI3K/Akt-independent manner [16]. However, to date, there is no clinically useful biomarker that can be used to inform patient selection for trastuzumab therapy [17]. Analysis of mechanisms contributing to trastuzumab resistance in the context of well designed and prospective clinical trials with tumor samples taken before and after acquisition of resistance to trastuzumab is needed in this area of clinical research.

Several therapeutic avenues are undertaken to overcome trastuzumab resistance in breast cancer patients. Tyrosine kinase inhibitors (TKIs), such as neratinib and lapatinib, are tested either alone or in combination with trastuzumab for trastuzumab-resistant disease $[18,19]$. Small molecular inhibitors targeting PI3K (XL147 and BKM120), mTOR (everolimus and temsirolimus) and Hsp90 (tanespymicin) are also tested in Phase I and II clinical studies in trastuzumab-resistant breast cancer [2,20,21]. Combination of trastuzumab with another monoclonal antibody, which targets different epitope on HER2- pertuzumab is currently under clinical evaluation for the treatment of trastuzumab-resistant disease [22,23]. Antibody-drug conjugates $(\mathrm{ADC})$ are therapeutic agents where a monoclonal antibody is linked to highly cytotoxic compounds via a linker and used to deliver cytotoxic agent to the antigen positive tumor cell [24]. Ado-trastuzumab emtansine is an ADC which was tested and recently approved for the treatment of trastuzumab resistant breast cancers [25]. In addition to clinically tested therapies there are also several novel therapeutic approaches in different pre-clinical models which may hold promise in future. In cell culture experiments, successful targeting of trastuzumab resistant cells was achieved by using anti-HER2 conjugated silica gold nanoshells and near infrared laser [26]. In another preclinical study, anti-HER2 immunoconjugates were generated by linking human anti-HER2 scFv named Erbicin to either human RNase or to the Fc region of IgG1 [27]. Both immunoconjugates have significant activity against trastuzumab resistant breast cancer cells [27]. As development of these agents continues, more information will be acquired about their potential to overcome trastuzumab resistance in clinical studies. Identification of predictive biomarkers for trastuzumab resistance accompanied by development and clinical testing of novel agents in patients who progress on trastuzumab has potential to bring more effective and safer therapies.

Although there were multiple mechanisms of trastuzumabresistance proposed based on the clinical and preclinical studies, the question remains how the knowledge gained from these studies can be translated into the next generation of monoclonal antibodies to overcome therapeutic resistance to trastuzumab [2]. Based on literature and data from our laboratory [13], we propose a new approach by designing an antibody-drug conjugate (ADC) based on the mechanisms of trastuzumab resistance [2]. In this ADC, trastuzumab is conjugated to a small molecule that has ability to inhibit the cellular target(s) that has been demonstrated to contribute to trastuzumab-resistance. This proposed strategy may increase the magnitude and duration of the response to trastuzumab treatment [2].

Disclaimer: The information presented in this article reflects the views of the authors and does not represent the policy of the U.S. Food and Drug Administration.

*Corresponding author: Wen Jin Wu, Laboratory of Molecular Oncology, Division of Monoclonal Antibodies, Office of Biotechnology Products, Office of Pharmaceutical Science, Center for Drug Evaluation and Research, U.S. Food and Drug Administration, Bethesda, Maryland, USA, E-mail: Wen.Wu@fda.hhs.gov

Received April 25, 2012; Accepted April 27, 2012; Published April 29, 2012

Citation: Dokmanovic M, Wu WJ (2013) Mechanisms of Trastuzumab Resistance and Opportunities to Overcome Therapeutic Resistance. J Mol Biomark Diagn 4: e116. doi:10.4172/2155-9929.1000e116

Copyright: (C) 2013 Dokmanovic M, et al. This is an open-access article distributed under the terms of the Creative Commons Attribution License, which permits unrestricted use, distribution, and reproduction in any medium, provided the original author and source are credited 
Citation: Dokmanovic M, Wu WJ (2013) Mechanisms of Trastuzumab Resistance and Opportunities to Overcome Therapeutic Resistance. J Mol Biomark Diagn 4: e116. doi:10.4172/2155-9929.1000e116

\section{References}

1. Hudis CA (2007) Trastuzumab--mechanism of action and use in clinical practice. N Engl J Med 357: 39-51.

2. Dokmanovic M, Wu WJ (2011) Trastuzumab-resistance and breast cancer. In: Gunduz M, Gunduz E. editors. Breast Cancer - Carcinogenesis, Cell Growth and Signaling Pathways, In Tech Publisher.

3. Gusterson BA, Gelber RD, Goldhirsch A, Price KN, Save-Soderborgh J, et al. (1992) Prognostic importance of c-erbB-2 expression in breast cancer International (Ludwig) Breast Cancer Study Group. J Clin Oncol 10: 1049-1056.

4. Paik S, Hazan R, Fisher ER, Sass RE, Fisher B, et al.(1990) Pathologic findings from the National Surgical Adjuvant Breast and Bowel Project: prognostic significance of erbB-2 protein overexpression in primary breast cancer. J Clin Oncol 8: 103-112.

5. Slamon DJ, Godolphin W, Jones LA, Holt JA, Wong SG, et al. (1989) Studies of the HER-2/neu proto-oncogene in human breast and ovarian cancer. Science 244: 707-712.

6. Esteva FJ, Valero V, Booser D, Guerra LT, Murray JL, et al. (2002) Phase II study of weekly docetaxel and trastuzumab for patients with HER-2 overexpressing metastatic breast cancer. J Clin Oncol 20: 1800-1808.

7. Vogel CL, Cobleigh MA, Tripathy D, Gutheil JC, Harris LN, et al. (2002) Efficacy and safety of trastuzumab as a single agent in first-line treatment of HER2overexpressing metastatic breast cancer. J Clin Oncol 20: 719-726.

8. Sperinde J, Jin X, Banerjee J, Penuel E, Saha A, et al. (2010) Quantitation of p95HER2 in paraffin sections by using a p95-specific antibody and correlation with outcome in a cohort of trastuzumab-treated breast cancer patients. Clin Cancer Res 16: 4226-4235.

9. Nagy P, Friedlander E, Tanner M, Kapanen Al, Carraway KL, et al. (2005) Decreased accessibility and lack of activation of ErbB2 in JIMT-1, a herceptinresistant, MUC4-expressing breast cancer cell line. Cancer Res 65: 473-482.

10. Ritter CA, Perez-Torres M, Rinehart C, Guix M, Dugger T, et al. (2007) Human breast cancer cells selected for resistance to trastuzumab in vivo overexpress epidermal growth factor receptor and ErbB ligands and remain dependent on the ErbB receptor network. Clin Cancer Res 13: 4909-4919.

11. Nahta R, Yuan LX, Zhang B, Kobayashi R, Esteva FJ. (2005) Insulin-like growth factor-I receptor/human epidermal growth factor receptor 2 heterodimerization contributes to trastuzumab resistance of breast cancer cells. Cancer Res 65 11118-11128.

12. White CD, Li Z, Dillon DA, Sacks DB (2011) IQGAP1 protein binds human epidermal growth factor receptor 2 (HER2) and modulates trastuzumab resistance. J Biol Chem 286: 29734-29747.

13. Dokmanovic M, Hirsch DS, Shen Y, Wu WJ (2009) Rac1 contributes to trastuzumab resistance of breast cancer cells: Rac1 as a potential therapeutic target for the treatment of trastuzumab-resistant breast cancer. Mol Cancer Ther 8: 1557-1569.
14. Nagata $Y$, Lan KH, Zhou X, Tan M, Esteva FJ, et al. (2004) PTEN activation contributes to tumor inhibition by trastuzumab, and loss of PTEN predicts trastuzumab resistance in patients. Cancer Cell 6: 117-127.

15. Berns K, Horlings HM, Hennessy BT, Madiredjo M, Hijmans EM, et al. (2007) A functional genetic approach identifies the PI3K pathway as a major determinant of trastuzumab resistance in breast cancer. Cancer Cell 12: 395-402.

16. Zhang S, Huang WC, Li P, Guo H, Poh SB, et al. (2011) Combating trastuzumab resistance by targeting SRC, a common node downstream of multiple resistance pathways. Nat Med 17: 461-469.

17. De P, Hasmann M, Leyland-Jones B. (2013) Molecular determinants of trastuzumab efficacy: What is their clinical relevance? Cancer Treat Rev pii: S0305-7372 (13)00039-X.

18. Burstein $H J$, Sun $Y$, Dirix LY, Jiang $Z$, Paridaens $R$, et al. (2010) Neratinib, an irreversible ErbB receptor tyrosine kinase inhibitor, in patients with advanced ErbB2-positive breast cancer. J Clin Oncol 28: 1301-1307.

19. Blackwell KL, Burstein HJ, Storniolo AM, Rugo HS, Sledge G, et al. (2012) Overall survival benefit with lapatinib in combination with trastuzumab for patients with human epidermal growth factor receptor 2-positive metastatic breast cancer: final results from the EGF104900 Study. J Clin Oncol 30: 25852592.

20. Morrow PK, Wulf GM, Ensor J, Booser DJ, Moore JA, et al. (2011) Phase II study of trastuzumab in combination with everolimus (RAD001) in patients with HER2-overexpressing metastatic breast cancer who progressed on trastuzumab-based therapy. J Clin Oncol 29: 3126-3132.

21. Modi S, Stopeck A, Linden $H$, Solit D, Chandarlapaty S, et al. (2011) HSP90 inhibition is effective in breast cancer: a phase II trial of tanespimycin (17-AAG) plus trastuzumab in patients with HER2-positive metastatic breast cancer progressing on trastuzumab. Clin Cancer Res 17: 5132-5139.

22. Spicer J (2004) Technology evaluation: pertuzumab, Roche/Genentech/ Chugai. Curr Opin Mol Ther 6: 337-343.

23. Cortes J, Fumoleau P, Bianchi GV, Petrella TM, Gelmon K, et al. (2012) Pertuzumab monotherapy after trastuzumab-based treatment and subsequen reintroduction of trastuzumab: activity and tolerability in patients with advanced human epidermal growth factor receptor 2-positive breast cancer. J Clin Oncol 30: $1594-1600$

24. Teicher BA, Chari RV. (2011) Antibody conjugate therapeutics: challenges and potential. Clin Cancer Res 17: 6389-6397.

25. FDA approves kadcyla for breast cancer (2013) Cancer Discov 3: 366.

26. Carpin LB, Bickford LR, Agollah G, Yu TK, Schiff R, et al. (2011) Immunoconjugated gold nanoshell-mediated photothermal ablation of trastuzumab-resistant breast cancer cells. Breast Cancer Res Treat 125: 27 34.

27. Gelardi T, Damiano V, Rosa R, Bianco R, Cozzolino R, et al. (2010) Two nove human anti-ErbB2 immunoagents are active on trastuzumab-resistant tumours. $\mathrm{Br} J$ Cancer 102: 513-519. 